\title{
Invariability of relationship between the polar cap magnetic activity and geoeffective interplanetary electric field
}

\author{
O. A. Troshichev, N. A. Podorozhkina, and A. S. Janzhura \\ Arctic and Antarctic Research Institute, St. Petersburg, 199397, Russia \\ Received: 7 February 2011 - Revised: 18 July 2011 - Accepted: 19 July 2011 - Published: 31 August 2011
}

\begin{abstract}
The PC (polar cap) index characterizing the solar wind energy input into the magnetosphere is calculated with use of parameters $\alpha, \beta$, and $\phi$, determining the relationship between the interplanetary electric field $\left(E_{\mathrm{KL}}\right)$ and the value of magnetic activity $\delta F$ in the polar caps. These parameters were noted as valid for large and small $E_{\mathrm{KL}}$ values, and as a result the suggestion was made (Troshichev et al., 2006) that the parameters should remain invariant irrespective of solar activity. To verify this suggestion, the independent sets of calibration parameters $\alpha, \beta$, and $\phi$ were derived separately for the solar maximum (1998-2001) and solar minimum (1997, 2007-2009) epochs, with a proper choice of a quiet daily variation (QDC) as a level of reference for the polar cap magnetic activity value. The results presented in this paper demonstrate that parameters $\alpha, \beta$, and $\phi$, derived under conditions of solar maximum and solar minimum, are indeed in general conformity and provide consistent (within $10 \%$ uncertainty) estimations of the PC index. It means that relationship between the geoeffective solar wind variations and the polar cap magnetic activity responding to these variations remains invariant irrespective of solar activity. The conclusion is made that parameters $\alpha, \beta$, and $\phi$ derived in AARI\#3 version for complete cycle of solar activity (1995-2005) can be regarded as forever valid.
\end{abstract}

Keywords. Interplanetary physics (Interplanetary magnetic fields) - Magnetospheric physics (Polar cap phenomena; Solar wind-magnetosphere interactions)

\section{Introduction}

The PC index was introduced (Troshichev and Andrezen, 1985; Troshichev et al., 1988) to characterize magnetic activity in the polar caps caused by the solar wind coupling

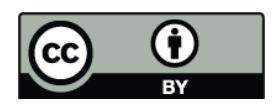

Correspondence to: O. A. Troshichev (olegtro@aari.nw.ru) with the magnetosphere. The concept of the DP2 disturbances (type 2 of polar magnetic disturbances unrelated to substorms) controlled by the geoeffective interplanetary electric field (Troshichev, 1982) served as a basis for the method of the index calculation. Relation of the 15-min PC index to the auroral electrojet indices $\mathrm{AL}$ and $\mathrm{AU}$ (characterizing the value of maximal negative, i.e. "lower", and positive, i.e. "upper", magnetic disturbances in the auroral zone) and AE (AU minus AL) was examined by Vennerstrom (1991) and Vennerstrom et al. (1991). Subsequently, a unified procedure was elaborated for derivation of the 1-min PCN and PCS indices (in the northern and southern polar caps, respectively) calculated by magnetic data from the Southern (Vostok station, Antarctica) and Northern (Thule station, the present name is Qaanaaq, Greenland) Hemispheres, respectively (Troshichev et al., 2006; Stauning et al., 2006). The unified PC index properly responds not only to the influence of the interplanetary electric field $\left(E_{\mathrm{KL}}\right)$ expressed by formula derived by Kan and Lee (1979), but also to the solar wind dynamic pressure pulses, irrespective of UT time, season, and location of stations in the Northern or Southern Hemispheres (Troshichev et al., 2007).

While analysing the unified procedure it was noted (Troshichev et al., 2006) that parameters $\alpha, \beta$, and $\phi$, determining the relationship between $E_{\mathrm{KL}}$ and the polar cap magnetic activity $\delta F$, are irrespective of values of these quantities, i.e. they are valid for low and large $E_{\mathrm{KL}}$ magnitudes. It made it possible to conclude that parameters $\alpha, \beta$, and $\phi$ should be invariant in course of the solar cycle (Troshichev et al., 2006). The parameters $\alpha, \beta$, and $\phi$ derived for full cycle of solar activity (1995-2005) were used in the procedure adopted in the Arctic and Antarctic Research Institute for the unified PC index derivation (the procedure known as AARI\#3 version, according to nomenclature proposed by McCreadie and Menvielle, 2010).

Just this version was used in all subsequent analyses of relationships between the PC index and magnetospheric substorm and geomagnetic storm fulfilled in AARI (Janzhura

Published by Copernicus Publications on behalf of the European Geosciences Union. 
et al., 2007; Troshichev et al., 2007, 2011; Troshichev and Janzhura, 2009). These analyses clearly demonstrated that the PC growth always preceded the magnetic disturbances, that substorms onset and magnetic storms beginnings occur when the PC value exceeds the defined threshold level of $\sim 2 \mathrm{mV} \mathrm{m}^{-1}$, that the intensity and variation of substorms are determined by the PC growth rate, that the storm magnitude (Dst peak) is proportional to the average PC value during the growth phase, and so on. These experimental facts testify that the PC index can be regarded as a reliable ground-based indicator of the solar wind energy that entered into the magnetosphere.

To verify the suggestion that parameters $\alpha, \beta$, and $\phi$ derived for full cycle of solar activity are valid equally for periods of low and high solar activity, it would be well to compare parameters $\alpha, \beta$, and $\phi$ derived independently for epochs of solar minimum and solar maximum. The passage of solar activity through the deep minimum in 2007-2009 made it possible to fulfill such analysis. In this paper we derive the parameters $\alpha, \beta$, and $\phi$ for the solar minimum epoch (1997, 2007-2009) and show their good conformity with the parameters derived for the solar maximum epoch activity (1998-2001). The analysis is preceded by demonstration of the crucial role of the quiet daily curve (QDC) as a level of reference for the polar cap magnetic activity in determination of parameters $\phi, \alpha$, and $\beta$.

\section{Peculiarities of the unified procedure for derivation of the PC index}

The idea behind the PC index is to use only ground based data with the once derived normalization coefficients to monitor the geoeffective impact of the solar wind on the magnetosphere. The normalization coefficients $\alpha$ and $\beta$ were derived as the statistically justified regression coefficients that connect values of the interplanetary electric field $E_{\mathrm{KL}}$ and the appropriate magnetic DP2 disturbance value $\delta F$ in different UT times and different days during a year:

$\delta F_{\phi}(k)=\alpha E_{\mathrm{KL}}(k)+\beta$

where the $\delta F(k)$ is value of the $\delta \boldsymbol{F}_{\phi}(k)$ vector mapped on the DP2 direction for $k$-th moment of time. The vectors $\delta \boldsymbol{F}_{\phi}(k)$ are calculated by the horizontal magnetic disturbances $(\delta H$, $\delta D)$ or $(\delta X, \delta Y)$ counted from the quiet daily curve variation. The vectors $\delta \boldsymbol{F}_{\phi}(k)$ are rotated by an angle $\phi$ to assign them with the DP2 equivalent current system and then the corresponding value $\delta F(k)$ is calculated. $E_{\mathrm{KL}}(k)$ is the interplanetary electric field calculated for $k$-th moment from the formula of Kan and Lee (1979) by the satellite measurements of the solar wind parameters in space, shifted to $12 R_{\mathrm{E}}$.

Thus, the technique for the coefficients calculation included the following steps:

- Determination of the magnetic disturbance vector $\delta \boldsymbol{F}_{\phi}(k)$ for each $k$-th moment of time,
- Definition of angle $\phi$ determining the $\delta \boldsymbol{F}_{\phi}(k)$ vector projection on the DP2 direction,

- Determination of the appropriate polar cap magnetic DP2 disturbance value $\delta F(k)$,

- Determination of the electric field value $E_{\mathrm{KL}}(k)$ for each $k$-th moment of time,

- Derivation of the statistically justified coefficients $\alpha$ and $\beta$, determining the relationship between $E_{\mathrm{KL}}$ and $\delta F$.

The linear regression coefficients $\alpha$ and $\beta$ were derived by the linear relation (1) for each 5-min $k$-th interval of data forming the "learning" data-set (in our case - 1997, 20072009). The coefficients $\alpha$ and $\beta$ were calculated for all angles $\phi$ in range $\pm 90^{\circ}$ from the suggested dawn-dusk orientation of the DP2 disturbance vectors in the near-pole region. When the correlation coefficient reaches the maximum, just that angle $\phi$ was chosen and the appropriate coefficients $\alpha$ and $\beta$ were taken for that UT time and month. To eliminate random oscillations, the 5-min values were subjected to a 6-point running locally weighted scatterplot smoothing (LOWESS) that is resistant to outliers; the 6-point smoothed values were then averaged for 4 years $(1997,2007-2009)$. As a result, the averaged 1-min parameters $\alpha, \beta$, and $\phi$ were derived for each UT time during a year. These parameters are used to calculate the $\mathrm{PC}$ indices for any time through any day of the year:

$\mathrm{PC}=\xi(\delta F-\beta) / \alpha$

The dimensionality of scale coefficient $\xi$ was taken as $\mathrm{mV} / \mathrm{m} / \mathrm{nT}$ in the unified procedure (Troshichev et al., 2006), so that the PC index is expressed in $\mathrm{mV} \mathrm{m}^{-1}$, which makes it convenient to compare with $E_{\mathrm{KL}}$.

In the AARI\#3 procedure the quiet daily geomagnetic variation - "quiet day curve" (QDC) - is calculated automatically in the on-line regime for both polar cap stations of Thule and Vostok. An automatic method for the QDC derivation is described in detail in Janzhura and Troshichev (2008). The method includes the automatic distinction of the quietest periods while using the geomagnetic variations parameterization, calculation of the proper quiet daily variation for certain days, reconstruction of QDC for each day of the elapsed period, and extrapolation of QDC for the subsequent period. The method ensures statistically reliable QDCs even for epochs of the solar maximum activity, when fully quiet days are practically absent. The second peculiarity of the procedure adopted in AARI is allowance for the interplanetary magnetic field (IMF) sector structure (SS). The SS influence, determined by the $B_{\mathrm{y}} \mathrm{IMF}$ component, leads to regular distortions of the DP2 current system. As a result, the daily run of the polar cap magnetic activity changes in such a manner that the daily mean value of activity either increases or decreases, being dependent on the sign of sector structure. A method for identification of the sector structure by the ground 

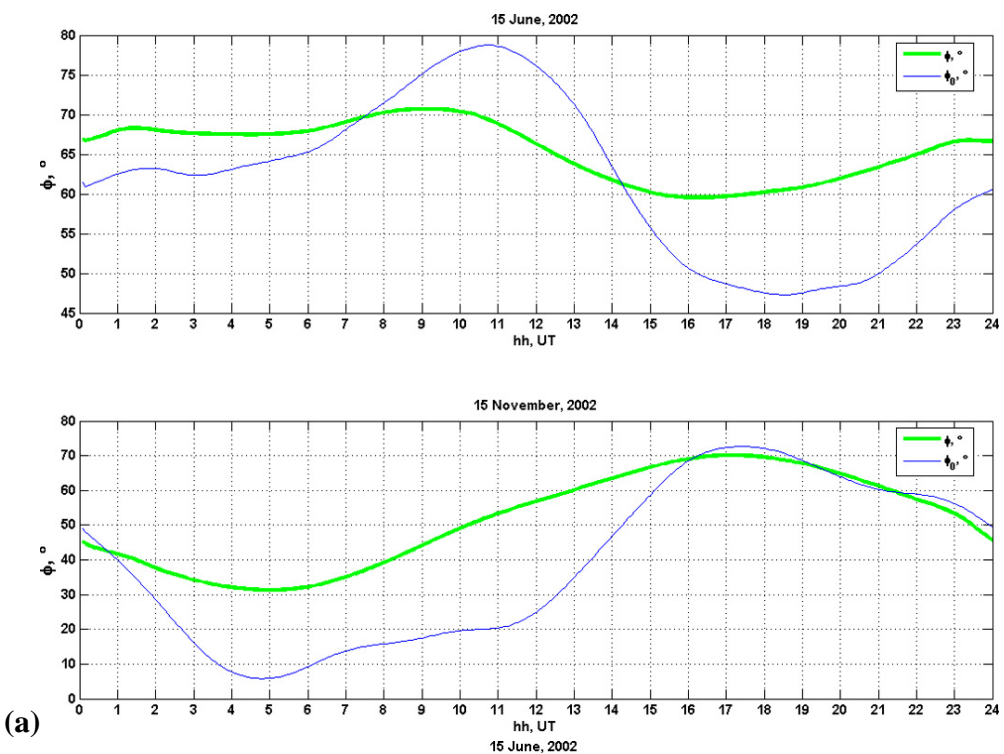

a)

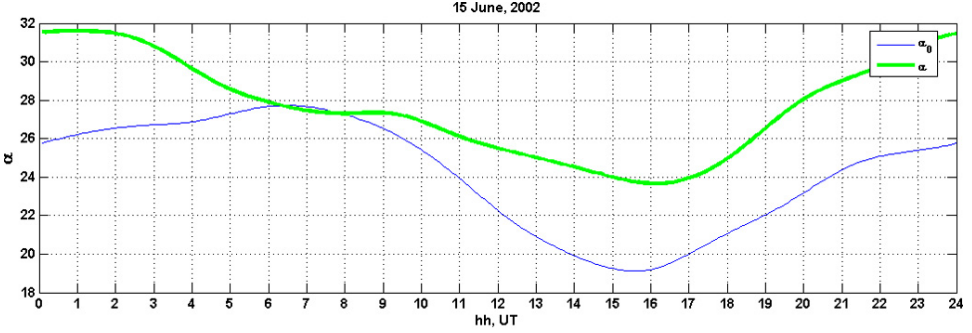

(b)
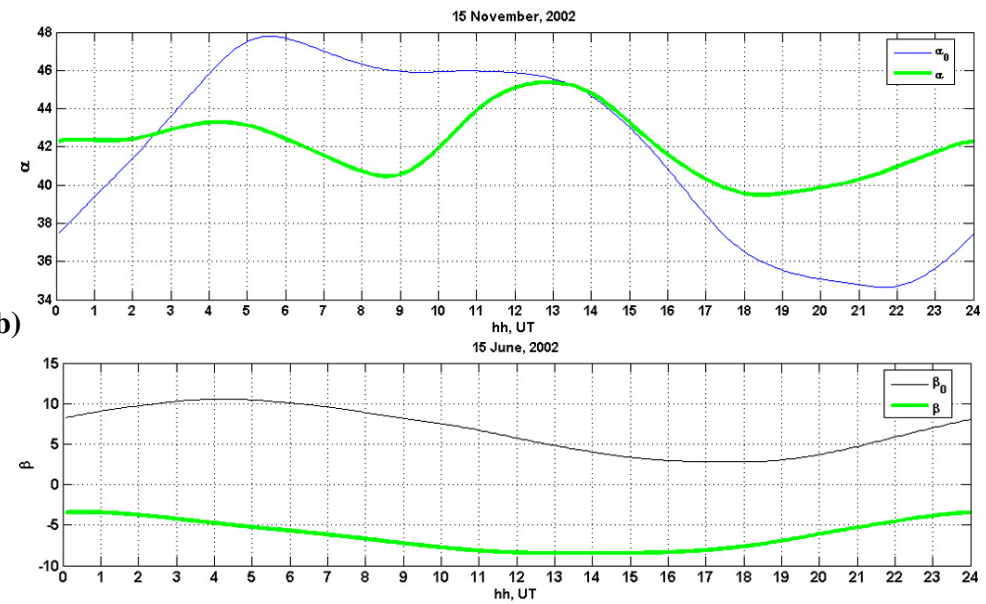

(c)

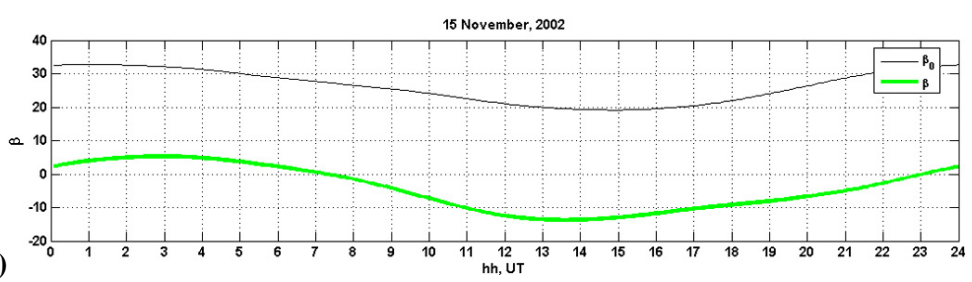

Fig. 1. Daily variation of angle $\phi_{0}$ (a), slope of regression line $\alpha_{0}$ (b), and intersection $\beta_{0}$ (c) derived without using QDC (thin lines) along with parameters $\phi, \alpha$, and $\beta$ derived with inclusion of QDC (thick lines) for the same winter (15 June) and summer (15 November) days of 2002 at the Vostok station. 

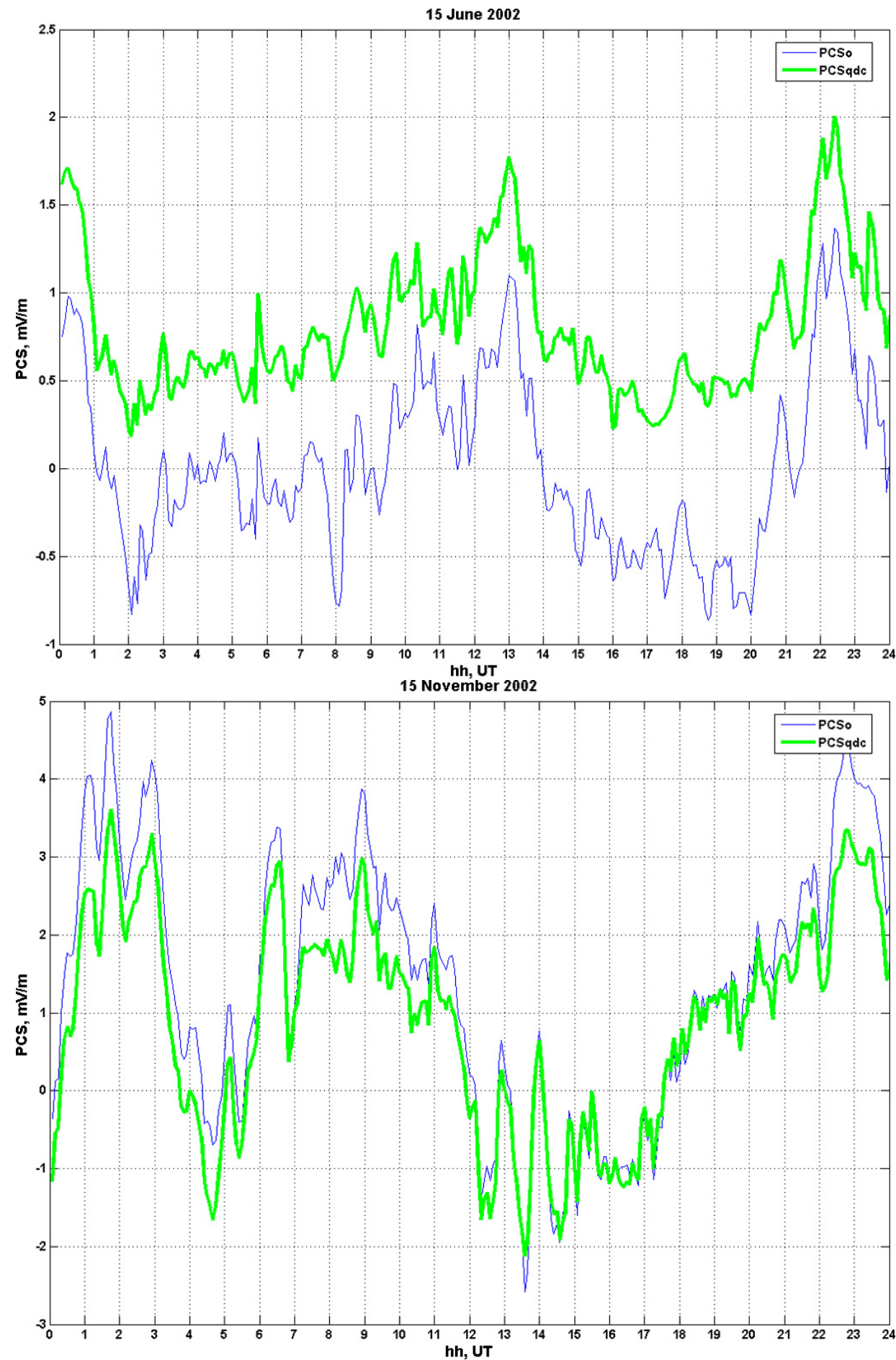

Fig. 2. $\mathrm{PCS}_{\mathrm{QDC}}$ indices calculated for 15 June and 15 November 2002 with a QDC (thick lines) and $\mathrm{PCS}_{0}$ derived without using a QDC (thin lines).

magnetic data and its consideration in the QDC calculation is presented in Janzhura and Troshichev (2011). The method of the automatic "on-line" derivation of the QDC irrespective of solar and magnetic activity and the IMF sector structure is one of the main advantages of the AARI\#3 procedure that ensures online calculation of PC index. 


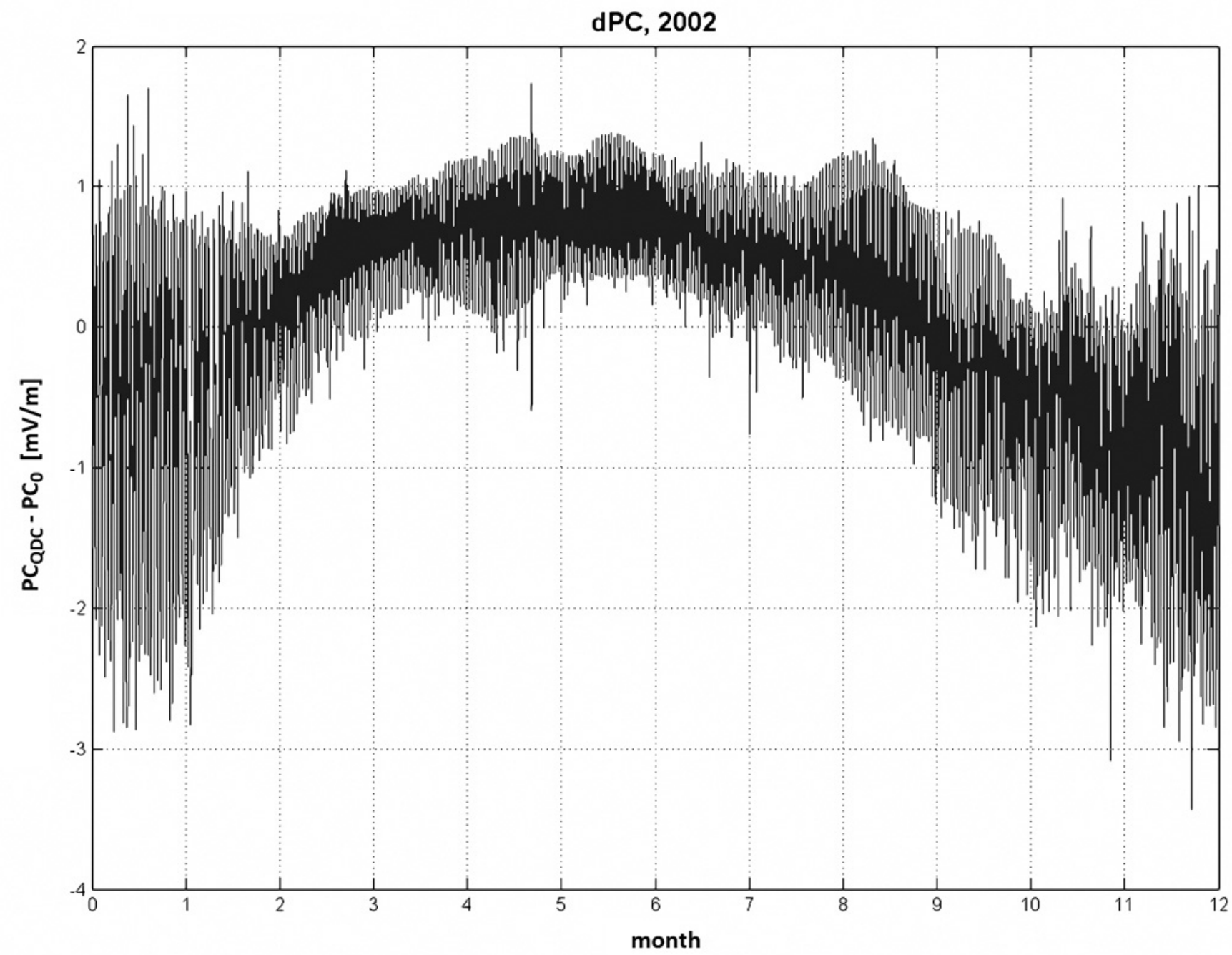

Fig. 3. Seasonal variation of the differences between the PCS index values calculated with a $\mathrm{QDC}\left(\mathrm{PC}_{\mathrm{QDC}}\right)$ and without a $\mathrm{QDC}\left(\mathrm{PC}_{0}\right)$ in 2002.

\section{Role of the QDC in determination of parameters $\phi, \alpha$, and $\beta$}

The steadiness of parameters $\phi, \alpha$, and $\beta$ for separate years was analyzed by Papitashvili et al. (2001) and Stauning et al. (2006). In Papitashvili et al. (2001), the coefficients $\alpha$ and $\beta$ for each year were calculated using three year running means in the solar wind and ground data, without reference to daily quiet variation. The authors found that coefficients are not similar for each year of solar cycle epoch, and the conclusion was made that the normalization parameters are not invariable and, therefore, they should be recalculated each year of solar cycle epoch.

In the procedure adopted by the Danish Meteorological Institute, the varying quiet level is derived to account the polar magnetic disturbances related to $E_{\mathrm{KL}}$ variations. According to description of the procedure given in Stauning et al. (2006), "the quiet day level (QL) is composed from hourly values by making a weighted average of data for each UT hour through the month. In order to enhance the systematic variations and suppress excursions related to singular events, the QL values are smoothed both with respect to UT hour and with respect to month. The smoothing is done by averaging a series of consecutive hours around the selected UT hour and a series of months around the selected month using a Gaussian weight function. For series of data back in time, the process of deriving monthly values of QL for each UT hour is usually extended over more than one year, typically 3 consecutive years, in order to minimize irregular variations caused, e.g. by lengthy intervals of magnetic storm conditions. The QL data defined this way are referred to the middle of the 3 years interval". Although parameters $\alpha, \beta$, and $\phi$ derived from above described procedure did not demonstrate a dependence on the solar activity cycle, their steadiness is 

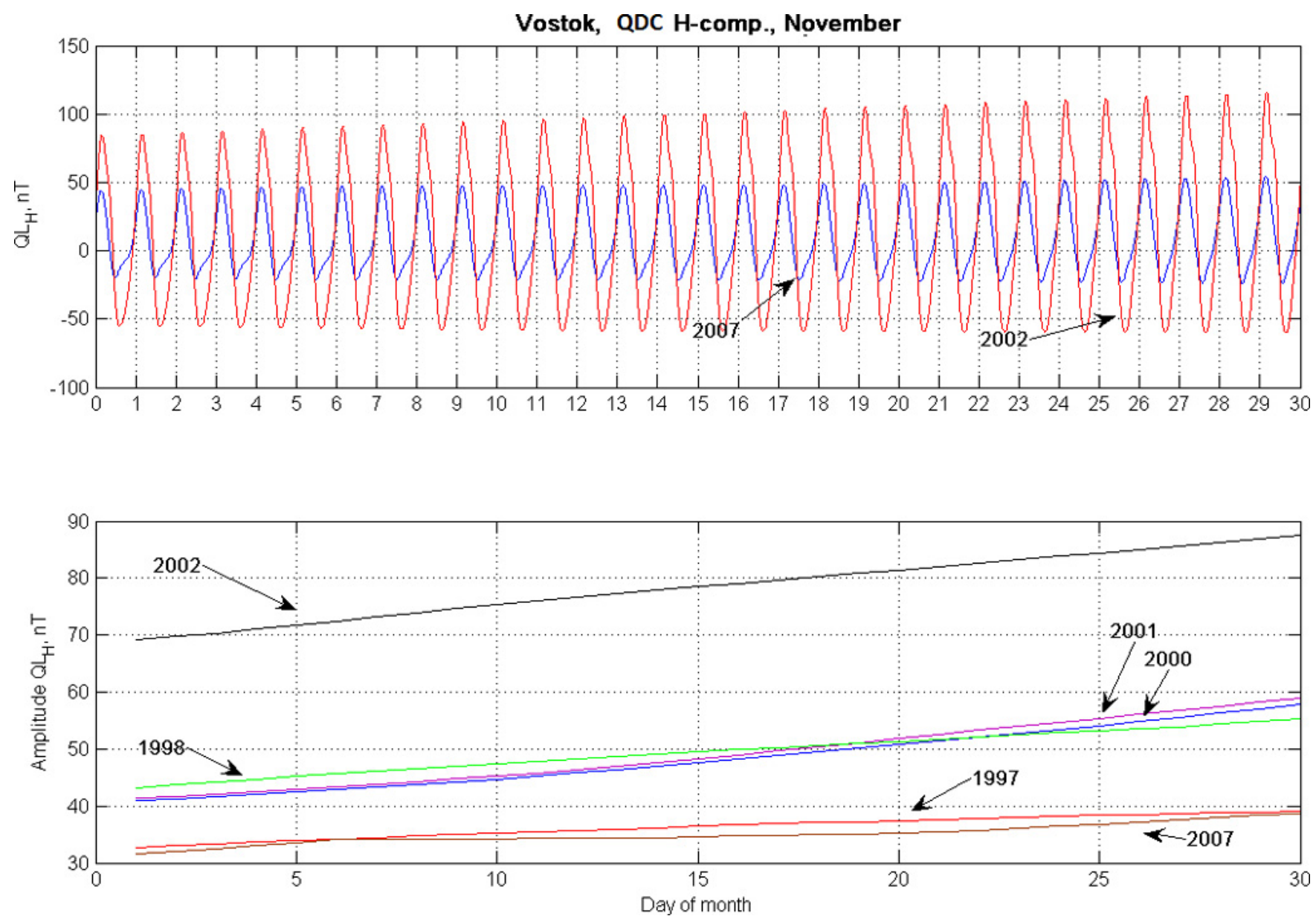

Fig. 4. Variation of the QDC in the H component at Vostok station for Novembers of 2002 and 2007 (upper panel) and the QDC amplitude trends during November months for several years of the solar cycle (lower panel).

rather a consequence of the strong smoothing effect where the months related to quite different levels of solar activity are united in the one smoothing group.

Since neither Papitashvili et al. (2001) nor Stauning et al. (2006) took into account the actual QDC changes during the month under the examination, the other factors, such as the IMF sector structure, the regular and irregular changes in the solar UV irradiation, and so on, can affect the value of polar cap magnetic activity. To demonstrate the QDC role in derivation of $\alpha, \beta$, and $\phi$ parameters, the parameters derived with inclusion of the QDC and without QDC should be compared. To provide such comparison, in our analysis we used the same experimental data (satellite measurements of $E_{\mathrm{KL}}$ and magnetic data from Vostok for 1998-2001) to derive a set of parameters $\alpha_{0}, \beta_{0}$, and $\phi_{0}$ without including the QDC.

Results of this calculation - angle $\phi_{0}$, slope of regression line $\alpha_{0}$ and intersection $\beta_{0}-$ are shown in Fig. 1 for winter and summer days at the Vostok station (15 June and 15 November 2002, respectively) along with parameters $\phi, \alpha$, and $\beta$ derived for the same days with inclusion of QDC. One can see that angle $\phi_{0}$ (Fig. 1a) demonstrates much larger magnitude of daily variation $\left(\sim 30^{\circ}\right.$ in winter and $\sim 70^{\circ}$ in summer) than angle $\phi$ calculated with inclusion of QDC $\left(\sim 10^{\circ}\right.$ and $\sim 30^{\circ}$, respectively). The same regularity is typical of the slope value (Fig. 1b), especially in summer period $\left(\Delta \alpha_{0} \sim 14, \Delta \alpha \sim 6\right)$. As for intersection (Fig. 1c), coefficients $\beta_{0}$ are always positive (from 3 to 11 in winter and from 20 to 35 in summer), whereas coefficients $\beta$ are predominantly negative (from -3 to -8 in winter and from 5 to -15 in summer). Thus, parameters $\phi_{0}, \alpha_{0}$, and $\beta_{0}$ derived without QDC demonstrate much large daily variability than parameters $\phi, \alpha$, and $\beta$ derived with inclusion of QDC.

To estimate effect of differences in parameters $\phi, \alpha$, and $\beta$ on the $\mathrm{PC}$ index value, the appropriate indices $\mathrm{PC}_{0}$ and $\mathrm{PC}_{\mathrm{QDC}}$ have been calculated. Figure 2 shows the variation of $\mathrm{PC}_{0}$ and $\mathrm{PC}_{\mathrm{QDC}}$ indices on the same days: 15 June and 15 November 2002. It is seen the strong similarity in behaviour of $\mathrm{PC}_{0}$ and $\mathrm{PC}_{\mathrm{QDC}}$ indices, but their values turn out to be different. In the winter day of 15 June, the $\mathrm{PC}_{\mathrm{QDC}}$ values (thick line) are regularly $\sim 0.5-1.3 \mathrm{mV} \mathrm{m}^{-1}$ above the 

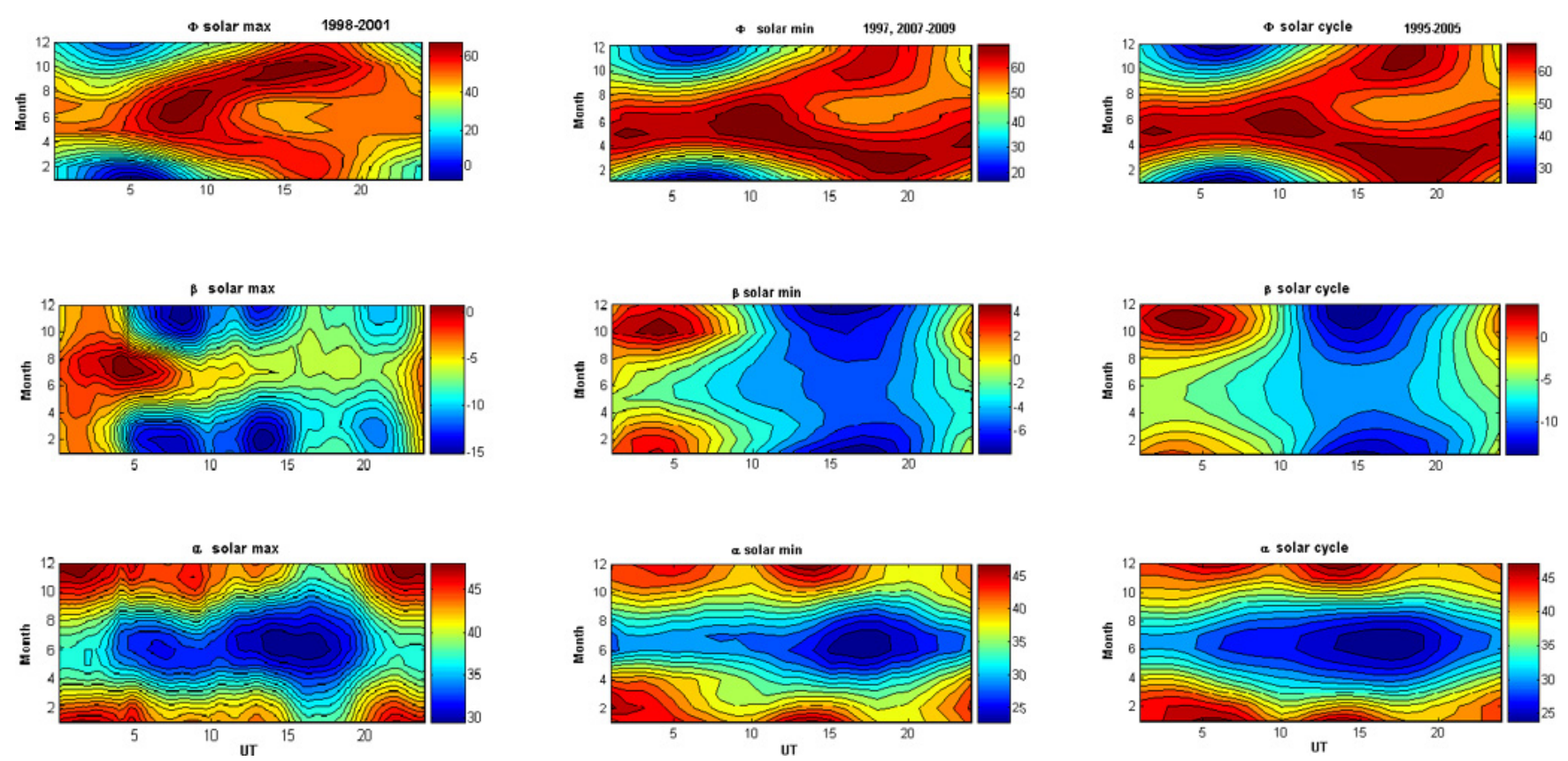

Fig. 5. Parameters $\phi, \beta$, and $\alpha$ derived for Vostok station independently for epoch of solar maximum (1998-2001) [Troshichev et al., 2006], for epoch of solar minimum (1997, 2007-2008), and for complete cycle of solar activity (1995-2005) (AARI\#3 version); the axis of abscises being for UT and axis of ordinates being for month.

$\mathrm{PC}_{0}$ values (thin line). In the summer season of 15 November, the $\mathrm{PC}_{0}$ values (thin line) are $\sim 1-1.5 \mathrm{mV} \mathrm{m}^{-1}$ above $\mathrm{PC}_{\mathrm{QDC}}$ (thick line) during day-time hours, but both quantities are practically coincident around local night (16:00 UT). The differences $\mathrm{dPC}=\mathrm{PC}_{\mathrm{QDC}}-\mathrm{PC}_{0}$ display the daily variation, the character of which is strongly changed from season to season, as it is clearly seen in Fig. 3. During the winter months the $\mathrm{PC}_{\mathrm{QDC}}$ index is larger than $\mathrm{PC}_{0}$ index and the amplitude of daily variation in average does not exceed $1 \mathrm{mV} \mathrm{m}^{-1}$, whereas in the summer season $\mathrm{PC}_{0}$ is larger, as a rule, than $\mathrm{PC}_{\mathrm{QDC}}$, with amplitudes of daily variation as large as $3 \mathrm{mV} \mathrm{m}^{-1}$. Thus, inconsistencies between the $\mathrm{PC}$ indices, calculated with a QDC and without QDC, can reach significant values, and this circumstance directly relates to conclusions about the variability of parameters $\phi, \alpha$, and $\beta$ in the solar activity cycle claimed by Papitashvili et al. (2001).

\section{Invariability of parameters $\alpha, \beta$, and $\phi$ in the solar activity cycle}

To demonstrate the independence of the parameters $\alpha, \beta$, and $\phi$ on solar cycle activity, when the QDC is taken into account, we derived an independent set of parameters for the solar minimum epoch $(1997,2007-2009)$ and compared them with the parameters obtained in Troshichev et al. (2006) for the solar maximum epoch (1998-2001). To demonstrate how much the difference in the QDC in solar maximum and minimum epochs could be, we show in Fig. 4 the QDC cal- culated for H-component at Vostok station in November of 2002 and 2007 (upper panel), and the QDC amplitude trends during November months of several years of the solar cycle (low panel). One can see that the QDC amplitude can change in range from 70-90 nT to 30-40 nT when passing from the epoch of solar maximum in 2002 to the epoch of solar minimum in 1997 and 2007.

The proper QDCs for solar minimum years have been taken as a level of reference to evaluate the magnetic disturbance values $\delta F(k)$ at Vostok and the obtained values $\delta F(k)$ have been correlated with the appropriate $E_{\mathrm{KL}}$ quantities to derive the parameters $\alpha, \beta$, and $\phi$ typical of solar minimum. Figure 5 shows plot of parameters $\alpha, \beta$, and $\phi$ derived for the years of maximal solar activity 1998-2001 (left column, adopted from Troshichev et al., 2006) in comparison with plot of the parameters derived for years of minimal solar activity 1997, 2007-2009 (middle column). Figure 5 (right column) shows plot of the parameters $\alpha, \beta$, and $\phi$ derived for complete cycle of the solar activity (1995-2005), which are used in AARI\#3 version. One can see the total consistency of patterns for angles $\phi$ and coefficients $\alpha$ and $\beta$ if difference in scales for three columns is taken into account. To emphasize any differences in behaviour of parameters $\alpha, \beta$, and $\phi$ in course of solar maximum and solar minimum epochs, the coefficients presented in the left and middle columns of Fig. 5 have been applied to calculate the appropriate values $\left(\mathrm{PC}_{\text {solmax }}\right)$ and $\left(\mathrm{PC}_{\text {solmin }}\right)$ for the same year 2001. 

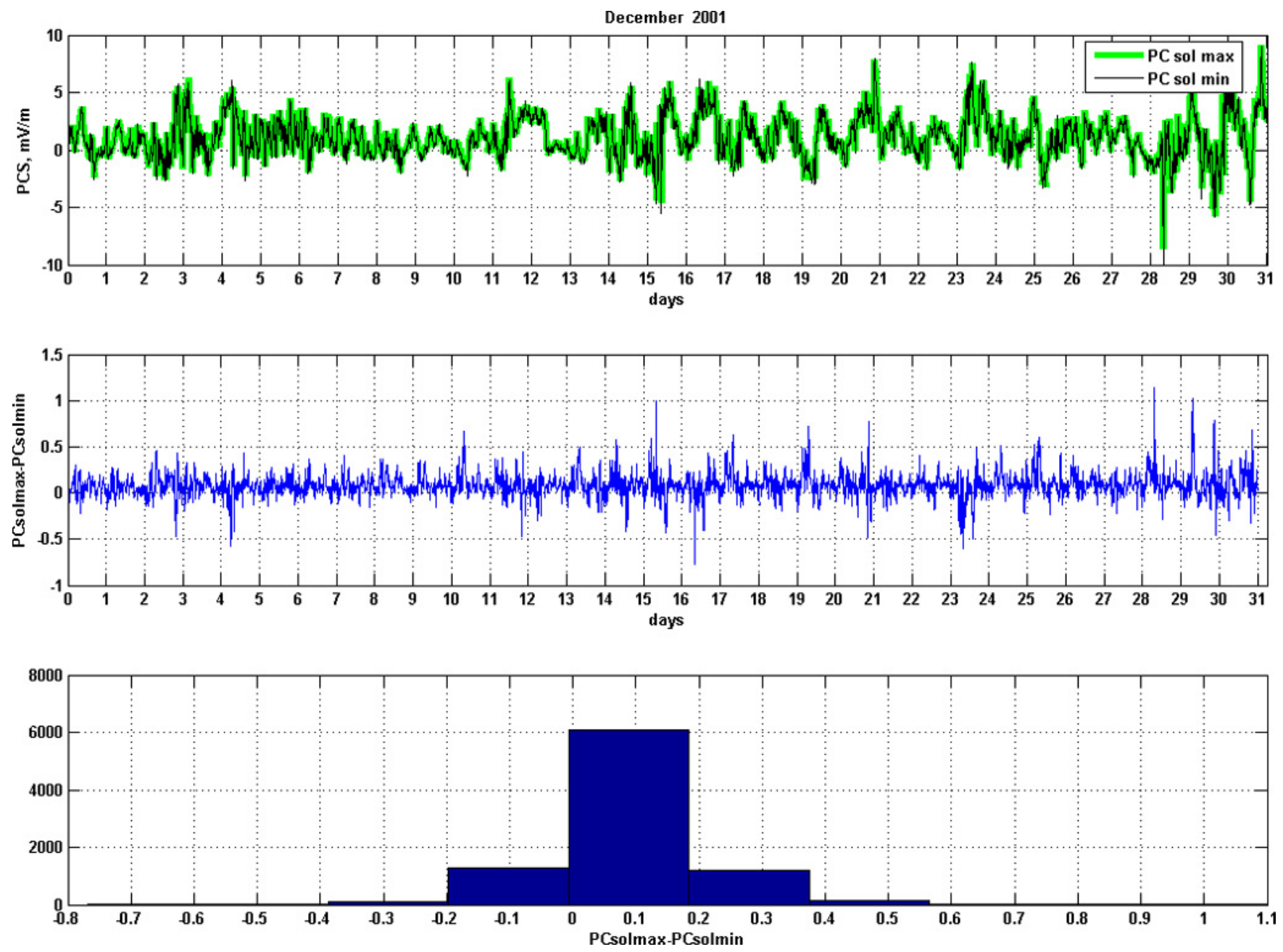

Fig. 6. Indices $\mathrm{PC}_{\text {solmax }}$ (thick line) and $\mathrm{PC}_{\text {solmin }}$ (thin line) calculated for Vostok in December 2001 with use of two independent sets of parameters $\phi, \alpha$ and $\beta$ (upper panel), differences between indices $\mathrm{PC}_{\text {solmax }}$ and $\mathrm{PC}_{\text {solmin }}$ in a larger scale (middle panel), and distribution plots for the differences (lower panel).

The upper panels of Figs. 6 and 7 show the variations of two sets of the PCS indices in summer (December) and winter (June) months of 2001. The middle panels show the differences $\left(\mathrm{PC}_{\text {solmax }}-\mathrm{PC}_{\text {solmin }}\right)$ in a larger scale to show a diversity between the two indices. The lower panels in Figs. 6 and 7 demonstrate the distribution plots for the differences. One can see that the value of differences in the summer season (Fig. 6) fluctuates in the range of $\pm 0.3 \mathrm{mV} \mathrm{m}^{-1}$, the mean difference being about zero. In the winter season (Fig. 7), the dispersion of the difference values is roughly the same, but the level of mean difference is of $\sim 0.18 \mathrm{mV} \mathrm{m}^{-1}$, i.e. there is a negligible underestimation of the $\mathrm{PC}$ index. Figure 8 shows the variations of two sets of the PCS indices throughout the year 2001, the lower panel demonstrating the differences $\left(\mathrm{PC}_{\text {solmax }}-\mathrm{PC}_{\text {solmin }}\right)$ in a larger scale. The result is the same: the mean difference between two sets of data fluctuates in the range $\pm 0.3 \mathrm{mV} \mathrm{m}^{-1}$ around roughly zero level. It means that parameters $\alpha, \beta$, and $\phi$ derived by data of the solar minimum epoch can be used for calculation of the PC index in years of solar maximum, the mean difference $\left(\mathrm{PC}_{\text {solmax }}-\mathrm{PC}_{\text {solmin }}\right)$ remaining below the usual $\mathrm{PC}$ index noise level $\left(\sim 0.5 \mathrm{mV} \mathrm{m}^{-1}\right)$. Taking into account the quite insufficient statistical validity of coefficients (mean of only 4 quantities), the results seem to be quite reasonable.

\section{Discussion}

One can see that use of a QDC as a level of reference for values of the polar cap magnetic disturbance leads to a consistency in the calibration parameters $\alpha, \beta$, and $\phi$ derived independently for epochs of solar maximum and solar minimum, and provides a good agreement in the behaviour of the PC indices calculated by these two sets of coefficients. At the same time it may be noted that difference between two sets of the PC indices increases with increasing the activity 

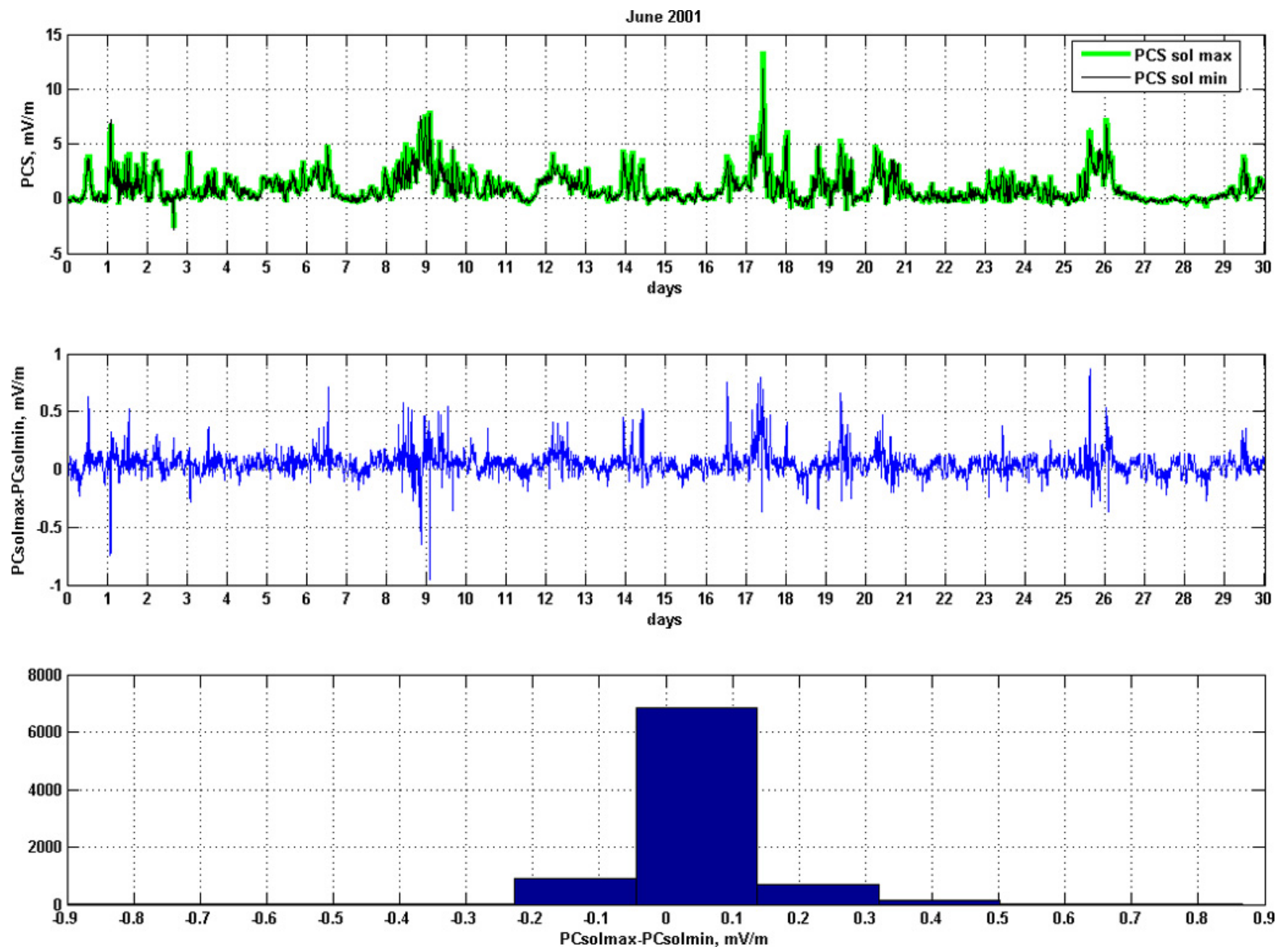

Fig. 7. Indices $\mathrm{PC}_{\text {solmax }}$ (thick line) and $\mathrm{PC}_{\text {solmin }}$ (thin line) calculated for Vostok in June 2001.

level, remaining in average in range $\sim 10 \%$ of the PC value. Is this difference acceptable or not?

To answer this question, we have to take into account that conditions during a long period (epoch of solar activity or separate year) can not be completely quiet or completely disturbed. The disturbed intervals alternate with quiet intervals during solar maximum epochs, and quiet intervals alternate with disturbed intervals during the solar minimum epochs. Parameters $\alpha, \beta$, and $\phi$ are derived as values statistically justified for average conditions. The average parameter value for solar maximum is shifted to one side, the average parameter value for solar minimum is shifted to the opposite side, the average parameter value for transient periods between years of solar minimum and solar maximum epochs lying between "maximum" and "minimum" positions. In any case the statistically justified parameter is average value, which can not be equally matched to entire variety of conditions.

Therefore, we are faced with a dilemma: either to derive parameters that most closely correspond to varying external conditions or to rest contended with average parameters. The first approach is reduced to division of the whole volume of data into separate parts according to power of different factors determining the PC index value (such as coupling function $E_{\mathrm{KL}}$, solar wind dynamic pressure pulses, solar proton flux, opposite effect of the azimuthal IMF component in the opposite polar caps, and so on) and calculation of parameters $\alpha, \beta$, and $\phi$ separately for each part. This approach is quite attainable and would provide the perfect evaluation of parameters for certain conditions and, therefore, the exact estimation of the PC index. However, calculation of the PC index in frameworks of this approach is possible only on condition that all factors are well known and, therefore, can not be used for such an applied task as the monitoring of the current state the of magnetosphere.

The second approach makes it possible to derive the parameters $\alpha, \beta$, and $\phi$ suitable for practical implementation irrespective of external conditions, but the values of the PC index in this case are estimated within the limits of $10 \%$ error. Taking into account that parameters $\alpha, \beta$, and $\phi$ for each UT moment were statistically justified by only 4 points for 

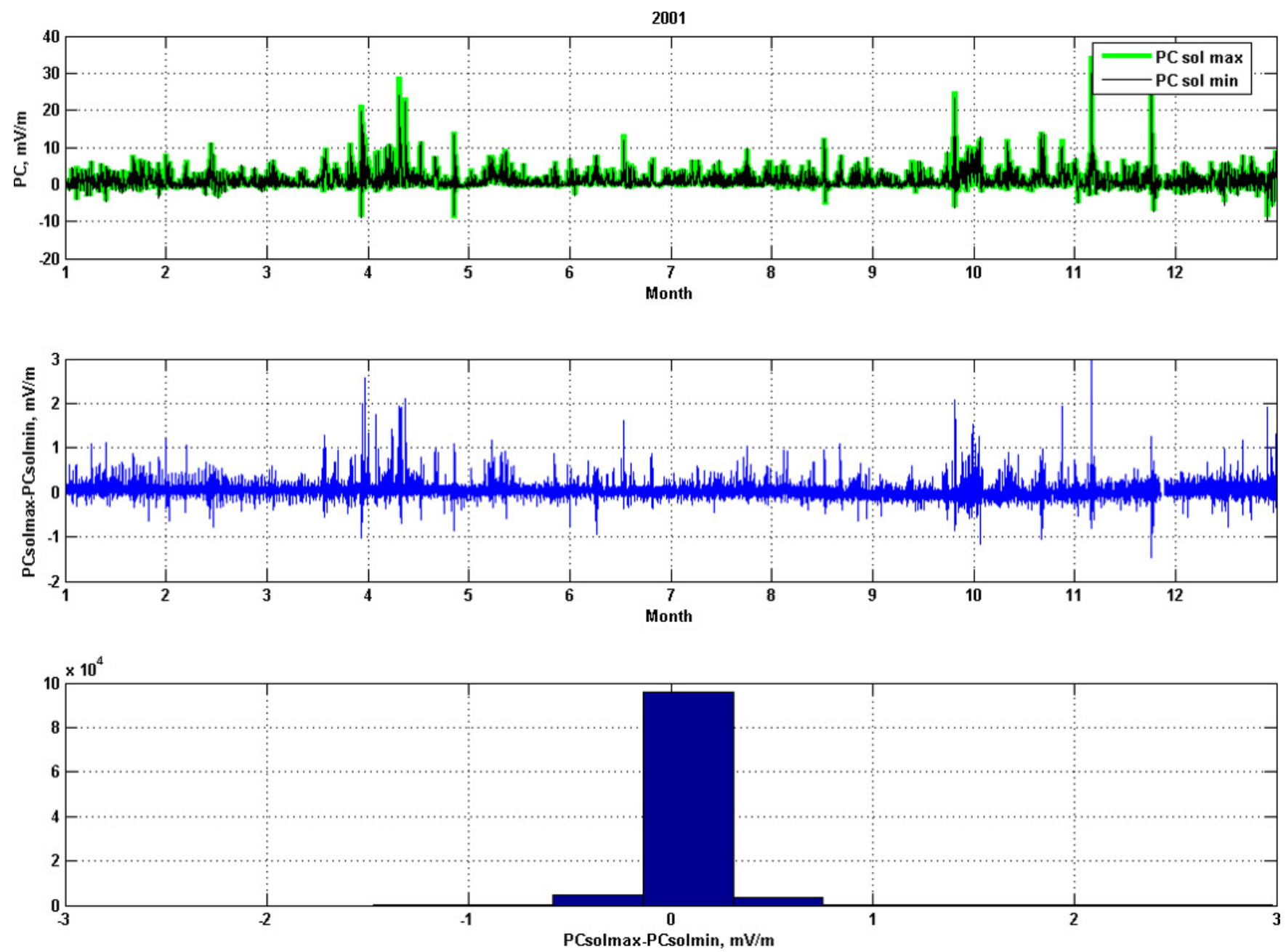

Fig. 8. Variations of indices $\mathrm{PC}_{\text {solmax }}$ (thick line) and $\mathrm{PC}_{\text {solmin }}$ (thin line) at Vostok throughout the year 2001 (upper panel), difference $\left(\mathrm{PC}_{\text {solmax }}-\mathrm{PC}_{\text {solmin }}\right)$ in a larger scale (middle panel), and distribution plots for the differences (lower panel).

the solar maximum epoch (1998-2001) as well as by 4 points for solar minimum epoch (1997, 2007-2009), the $10 \%$ uncertainty of the PC value estimation seems to be quite insignificant. It makes it possible to conclude that the relationship between the coupling function $E_{\mathrm{KL}}$ and the polar cap magnetic activity, responding to $E_{\mathrm{KL}}$, can be considered as independent of solar activity and, therefore, the parameters $\alpha, \beta$, and $\phi$ based on data for complete solar activity cycle (1995-2005, as in AARI\#3 version, see right column in Fig. 5) can be regarded as valid forever.

\section{Conclusion}

The use of a QDC as a level of reference for values of the polar cap magnetic disturbance leads to a close consistency in the calibration parameters $\alpha, \beta$, and $\phi$ calculated for epochs of solar maximum and solar minimum, and provides (within $10 \%$ uncertainty) agreement of the PC indices calculated by these independent sets of coefficients. Therefore, parameters $\alpha, \beta$, and $\phi$, which determine relations between the coupling function $E_{\mathrm{KL}}$ and the magnetic activity value $\delta F$, can be considered as invariant irrespective of the solar activity. It means that the relationship between the geoeffective solar wind variations and the polar cap magnetic activity responding to these variations does not change in the course of the solar cycle. Thus, once derived parameters of $\alpha, \beta$, and $\phi$ can be regarded as valid forever, provided that the appropriate QDCs are used.

Acknowledgements. Topical Editor R. Nakamura thanks B. Emery and M. Menvielle for their help in evaluating this paper. 


\section{References}

Janzhura, A. S. and Troshichev, O. A.: Determination of the running quiet daily geomagnetic variation, J. Atmos. Solar-Terr. Phys., 70, 962-972, 2008.

Janzhura, A. S. and Troshichev, O. A.: Identification of the IMF sector structure in near-real time by ground magnetic data, Ann. Geophys., 29, 1491-1500, doi:10.5194/angeo-29-14912011, 2011.

Janzhura, A., Troshichev, O., and Stauning, P.: Unified PC indices: Relation to the isolated magnetic substorms, J. Geophys. Res., 112, A09207, doi:10.1029/2006JA012132, 2007.

Kan, J. R. and Lee, L. C.: Energy coupling function and solar windmagnetosphere dynamo, Geophys. Res. Lett., 6, 577-580, 1979.

McCreadie, H. and Menvielle, M.: The PC index: review of methods, Ann. Geophys., 28, 1887-1903, doi:10.5194/angeo28-1887-2010, 2010, Corrigendum: Ann. Geophys., 29, 813814, doi:10.5194/angeo-29-813-2011, 2011.

Papitashvili, V. O., Gomova, L. I., Popov, V. A., and Rasmussen, O.: Northern Polar Cap magnetic activity index PCN: Effective area, universal time and solar cycle variations, DMI Scientific Report, SR-01-01, Copenhagen, Denmark, 57 pp., 2001.

Stauning, P., Troshichev, O., and Janzhura, A.: Polar Cap (PC) index. Unified PC-N (North) index procedures and quality, DMI Scientific Report, SR-06-04, 2006.

Troshichev, O. A.: Polar cap magnetic disturbances and fieldaligned currents, Space Sci. Rev., 32, 275-360, 1982.

Troshichev, O. A. and Andrezen, V. G.: The relationship between interplanetary quantities and magnetic activity in the southern polar cap, Planet Space Sci., 33, 415-419, 1985.
Troshichev, O. and Janzhura, A.: Relationship between the PC and AL indices during repetitive bay-like magnetic disturbances in the auroral zone, J. Atmos. Solar-Terr. Phys., 71, 1340-1352, 2009.

Troshichev, O. A., Andrezen, V. G., Vennerstrøm, S., and FriisChristensen, E.: Magnetic activity in the polar cap - A new index, Planet. Space Sci., 36, 1095-1102, 1988.

Troshichev, O., Janzhura, A., and Stauning, P.: Unified PCN and PCS indices: Method of calculation, physical sense and dependence on the IMF azimuthal and northward components, J. Geophys. Res., 111, A05208, doi:10.1029/2005JA011402, 2006.

Troshichev, O. A., Janzhura, A. S., and Stauning, P.: Magnetic activity in the polar caps: Relation to sudden changes in the solar wind dynamic pressure, J. Geophys. Res., 112, A11202, doi:10.1029/2007JA012369, 2007.

Troshichev, O., Sormakov, D., and Janzhura, A.: Relation of PC index to the geomagnetic storm Dst variation, J. Atmos. SolarTerr. Phys., 73, 611-622, doi:10.1016/j.jastp.2010.12.015, 2011.

Vennerstrom, S.: The geomagnetic activity index PC, Ph.D. Thesis, Scientific Report 91-3, Danish Meteorological Institute, 105 pp., 1991.

Vennerstrom, S., Friis-Christensen, E., Troshichev, O. A., and Andrezen, V. G.: Comparison between the polar cap index PC and the auroral electrojet indices AE, AL and AU, J. Geophys. Res., 96, 101-113, 1991. 